\title{
Behavioral responses to numerical differences when two invasive ants meet: the case of Lasius neglectus and Linepithema humile
}

\author{
Gema Trigos-Peral $[$ D S Sílvia Abril · Elena Angulo
}

Received: 9 March 2020/ Accepted: 3 November 2020/Published online: 20 November 2020

(C) The Author(s) 2020, corrected publication 2020

\begin{abstract}
Two of the world's most invasive ants, Linepithema humile and Lasius neglectus, are destined to overlap in range as they continue to spread throughout Europe. Although L. humile arrived first, and is therefore more numerically abundant, L. neglectus is the more behaviorally dominant of the two. We performed lab trials to determine whether $L$. humile could use numerical abundance to overcome the behavioral dominance of $L$. neglectus and whether the ants' behavioral patterns shifted when the species co-occurred. We found that $L$. neglectus was more aggressive when less abundant, whereas the opposite was true of $L$. humile. When $L$. neglectus was outnumbered, it employed aggressive
\end{abstract}

Electronic supplementary material The online version of this article (https://doi.org/10.1007/s10530-020-02412-4) contains supplementary material, which is available to authorized users.

\section{G. Trigos-Peral ( $\square)$}

Museum and Institute of Zoology, Polish Academy of

Sciences, Warsaw, Poland

e-mail: getriral@gmail.com; gema_trigos@miiz.waw.pl

S. Abril

Departament de Ciències Ambientals, Universitat de

Girona, Girona, Spain

E. Angulo

Université Paris-Saclay, CNRS, AgroParisTech, Ecologie

Systématique et Evolution, Orsay, France

E. Angulo

Estación Biológica de Doñana, CSIC, Sevilla, Spain behaviors, such as biting or chemical attacks, more frequently than L. humile; it also utilized a behavioral sequence that included mandible opening and biting. Our results for these species support the hypothesis that species modulate their behavior towards competitors, which facilitates the understanding of how multiple invasive ant species can co-occur in a given area. Moreover, our study shows that the co-occurrence of invasive species could result from the use of two strategies: (1) the Bourgeois strategy, in which aggressiveness changes based on numerical dominance and (2) the dear-enemy strategy, in which aggressiveness is reduced when competitors co-occur. Since these strategies may lead to territory partitioning, we suggest that the behavioral flexibility displayed by both species when they overlap may allow local co-occurrence and increase their likelihood of co-occurrence during their range expansion in Europe, which could have a negative cumulative impact on invaded areas.

Keywords Biodiversity - Confrontations · First detection of invasion - Invasive ants - Interspecific competition

\section{Introduction}

Invasive species are, by definition, alien species that have serious environmental, economic, and human health impacts, and they are considered to represent a global threat to biodiversity (Keller et al. 2011; Early 
et al. 2016). Invasions occur in stages, which are defined by the barriers that all exotic species must surmount: first, a species must arrive in an area outside its native range; second, it must survive and establish itself in that new area; and, third, it must spread to additional areas (Blackburn et al. 2011; Leung et al. 2012). Once a non-native species has arrived in a new area, its likelihood of establishment is determined by a variety of factors, including propagule size and composition (Simberloff 2009); abiotic conditions (e.g., climatic niche matching; Abellán et al. 2017); and biotic conditions (e.g., the resistance of the native community; Jeschke 2014).

Ants are a particularly prominent group of invasive species, with five species among the selection of the 100 worst invaders (Lowe et al. 2000) and 19 recognized by the IUCN Invasive Species Specialist Group [Global Invasive Species Database (http:// www.issg.org/database)]. Moreover, biogeographic barriers have been broken down frequently for ants, by human trade and travel (for example, more than 4 thousand border interceptions in USA and New Zealand over a period of 70 years, Bertelsmeier et al. 2018) and more than 240 alien ant species are known to have established outside their native range (Bertelsmeier et al. 2017). Because of this increased prevalence of ant invasive species (Suárez et al. 2005; Bertelsmeier et al. 2018) together with their trait similarity (e.g. small size, sociality and diversity of nesting habits, Bertelsmeier et al. 2017), many of these invasive species are coming into direct contact; this could result in their co-occurrence (e.g., Vonshak and Gordon 2015) or the displacement of one species by the other one (e.g., LeBrun et al. 2013; Wetterer 2017). Mechanisms of co-occurrence of invasive ant species are variable, including differences in microhabitat preferences (Morrison 1996; Trigos-Peral et al. 2020), behavioral differences (Morrison 1996; Holway and Suárez 1999; Axen et al. 2014; Bertelsmeier et al. 2015a) or different effectiveness in resource exploitation (Cerdá et al. 1997; Kneitel and Chase 2004; Berkley et al. 2010). Food resources can modulate the degree of aggressiveness displayed by the invasive species (Morrison 1996), which is usually mediated by a tradeoff between resource discovery and resource dominance (Zheng et al. 2008; Axen et al. 2014). Differences in aggressiveness among invasive ant species can facilitate their co-occurrence (Zheng et al. 2008; Bertelsmeier et al. 2015a, b); in fact, since invasive species are usually characterized as highly aggressive (Bertelsmeier et al. 2015a), their behavioral plasticity (Holway and Suárez 1999) becomes crucial to their success in an habitat invaded by multiple ant species. Thus, studies focused on the behavioral mechanisms facilitating the co-occurrence of invasive ant species are fundamental to understand their potential impact on the invaded areas and predict their future distribution.

Among the invasive ant species found in Europe two are highly successful: the Argentine ant, Linepithema humile, and the invasive garden ant or Anatolian ant (Czechowski et al. 2012), Lasius neglectus. Both L. humile and L. neglectus are among the 19 species listed as highly invasive by the IUCN Invasive Species Specialist Group (Lowe et al. 2000; Global Invasive Species Database [http://www.issg.org/ database]). Like other invasive ants, $L$. humile and $L$. neglectus display life history traits that are related to invasiveness: smaller size relative to related taxa, omnivory, mass recruitment to resources, polygyny (i.e., nests contain multiple queens), within-nest mating, budding dispersal, synanthropy (i.e., a preference for anthropogenic habitats), strong interspecific aggression, polydomy (i.e., presence of multiple interconnected nests), and unicoloniality. This latter characteristic results in low levels of intraspecific aggression, giving rise to supercolonies (Boomsma et al. 1990; Holway et al. 2002; Bertelsmeier et al. 2017). While L. neglectus does not seem to form distinct supercolonies in Europe (Ugelvig et al. 2008), it appears that $L$. humile has established at least three supercolonies in Europe: the Main supercolony, whose colonies are spread across the continent, as well as the Catalonian supercolony and the Corsican supercolony, whose colonies are restricted to specific locations within southwestern Europe (Giraud et al. 2002; Vogel et al. 2009; Blight et al. 2012).

These two species share ecological similarities and can therefore colonize the same types of habitats. However, they arrived at different times in Europe. Linepithema humile was first detected in Portugal in 1890 (Wetterer et al. 2009) and has since firmly established itself across the continent (Giraud et al. 2012). Lasius neglectus was first detected in Budapest in the 1970s and is continuing to spread across Europe (Espadaler et al. 2007). When the species overlap within a given area, differences in aggressiveness and/ or competitive strategies could determine whether the 
ants can successfully co-occur. Previous studies have found that $L$. neglectus is behaviorally more aggressive than L. humile (Bertelsmeier et al. 2015c), a trait that is greatly advantageous during interspecific interactions. That said, L. humile's colony density and size have increased over the course of its invasion (Diaz et al. 2014). Therefore, L. humile's earlier arrival in Europe means that it could be more numerically abundant and that it might already be well established when L. neglectus arrives at a given location, which could allow $L$. humile to exclude $L$. neglectus when the two species co-occur.

Moreover, because both species do co-occur in certain areas, we might expect changes in their competitive behavior over time. Indeed, invasive species have been observed to display behavioral shifts as a result of both genotypic and phenotypic plasticity (Axen et al. 2014; Strayer et al. 2006; Ricciardi et al. 2017). For example, L. humile can assess the relative abundance of competitors and respond accordingly. When competitors were present in high numbers, L. humile used an avoidance or escape strategy; when competitors were present in lower numbers, L. humile reacted more aggressively (Sagata and Lester 2009). This behavioral plasticity, in which competitor number determines a species' response, is known as the Bourgeois strategy (Maynard Smith 1982), and it could help invasive species successfully navigate the first stages of invasion, notably when they are facing numerically dominant species or other invasive species. It is therefore possible that an invasive species that has dominated a community for years can be replaced. This phenomenon, known as the "treadmill effect" (Thomas and Reid 2007), has been observed in different organisms. It appears to be most common in marine animals (Jackson 2015), but it has also been seen in some terrestrial systems. For example, in a midAtlantic community, mile-a-minute weed (Persicaria perfoliata [L.] H. Gross), an invasive Asian vine, was replaced by Japanese stiltgrass (Microstegium vimineum [Trin.] A. Camus), an invasive annual (Lake et al. 2011). In ants, invasive species replacements are also frequent; classic examples include the replacement of the red imported fire ant (Solenopsis invicta) by the imported crazy ant (Nylanderia fulva) in some regions of the Southeastern United States and Texas (LeBrun et al. 2013) or the replacement of the invasive Pheidole megacephala by L. humile on the islands of
Bermuda (Haskins \& Haskins 1965, 1988; Lieberburg et al. 1975; Wetterer 2017).

The dear-enemy strategy is another phenomenon that helps minimize the costs associated with continuous fights between co-occurring species (Boulay et al. 2007; Dimarco et al. 2010): interspecific confrontations have been found to be less aggressive when species co-occur than when they do not. Over the long term, continual highly aggressive competition for resources is expensive (Fisher 1954), and the resulting loss of workers and energy might exceed the benefits of competitive success. Thus, the dear-enemy strategy can lead to a form of equilibrium by decreasing aggressiveness among neighboring species and thus limiting the losses sustained by interacting colonies (Christensen and Radford 2017). The adoption of this strategy by invasive species might lead to the cooccurrence of multiple invasive species in a given area, which can have different outcomes and impacts in native communities (Simberloff and Von Holle 1999; Jackson 2015).

The objective of this study was to characterize the competitive abilities of $L$. humile and L. neglectus during paired confrontations to better understand the mechanisms that could allow their co-occurrence, which has been observed in at least one area (X. Espadaler, personal communication). We thus wanted to discern whether their co-occurrence could be explained by the Bourgeois strategy and/or the dearenemy strategy. First, to determine whether the Bourgeois strategy was in operation, we used lab trials in which we tested the effects of experimentally modifying species numerical dominance. If $L$. humile was employing the Bourgeois strategy, we predicted that, when numerically dominant, $L$. humile would act more aggressively toward L. neglectus; conversely, $L$. humile was expected to act less aggressively when numerically subordinate. Alternatively, if L. humile was not employing the Bourgeois strategy, we predicted that its numerical dominance would have no effect on its aggressiveness, which would allow the co-occurrence of the two species. Second, to determine whether the dear-enemy strategy was in operation, we used paired confrontations between ants from colony fragments collected in areas where the species do and do not co-occur. If the dear-enemy strategy was being employed, we predicted that the level of interspecific aggressiveness would be lower when the ants faced a familiar versus unfamiliar competitor. 
The utilization of this strategy could also allow the cooccurrence of the two species.

\section{Materials and methods}

Colony collection and maintenance

In October 2016, we collected four L. humile colony fragments from four different locations in Spain (Doñana National Park, Seville, Girona, and Sant Cugat) and three L. neglectus colony fragments from two locations in Spain (Sant Cugat and Gandía) and one location in Poland (Warsaw) (Fig. 1). The $L$. humile colony fragments came from two of the species' three European supercolonies (Blight et al. 2010, 2012, 2017). More specifically, the colony fragments from Doñana, Seville, and Girona came from the Main supercolony, and the colony fragment from Sant Cugat belonged to the Catalonian supercolony.

We collected large colony fragments (hereafter, colonies) to ensure that the lab colonies would function normally, given that having insufficient numbers of workers can detrimentally affect tasks such as foraging and territory defense (Burchill and Moreau 2016). Consequently, the lab colonies comprised 300-500 workers and at least one queen. Before the experiment began, all the colonies were maintained under the same constant conditions for 2 weeks to allow the ants time to acclimatize: we kept the room temperature at $23-25{ }^{\circ} \mathrm{C}$, used the photoperiod associated with the month of March in Poland (sunrise about 6 a.m. and sunset about 6 p.m.), and fed the ants a standard Bhatkar-Whitcomb diet (Bhatkar and Whitcomb 1970).

\section{Experimental design}

Our experiment consisted of staging confrontations between the two ant species. The aim was to simulate situations in which one invasive species had arrived and become established before the other invasive species. To this end, in each confrontation, one ant (referred to as numerically subordinate) from one species faced five ants from the other species (referred to as numerically dominant). There were thus two types of confrontations: one in which $L$. humile was numerically dominant (HUMdom: 5 L. humile vs. $1 \mathrm{~L}$. neglectus) and the other in which L. neglectus was

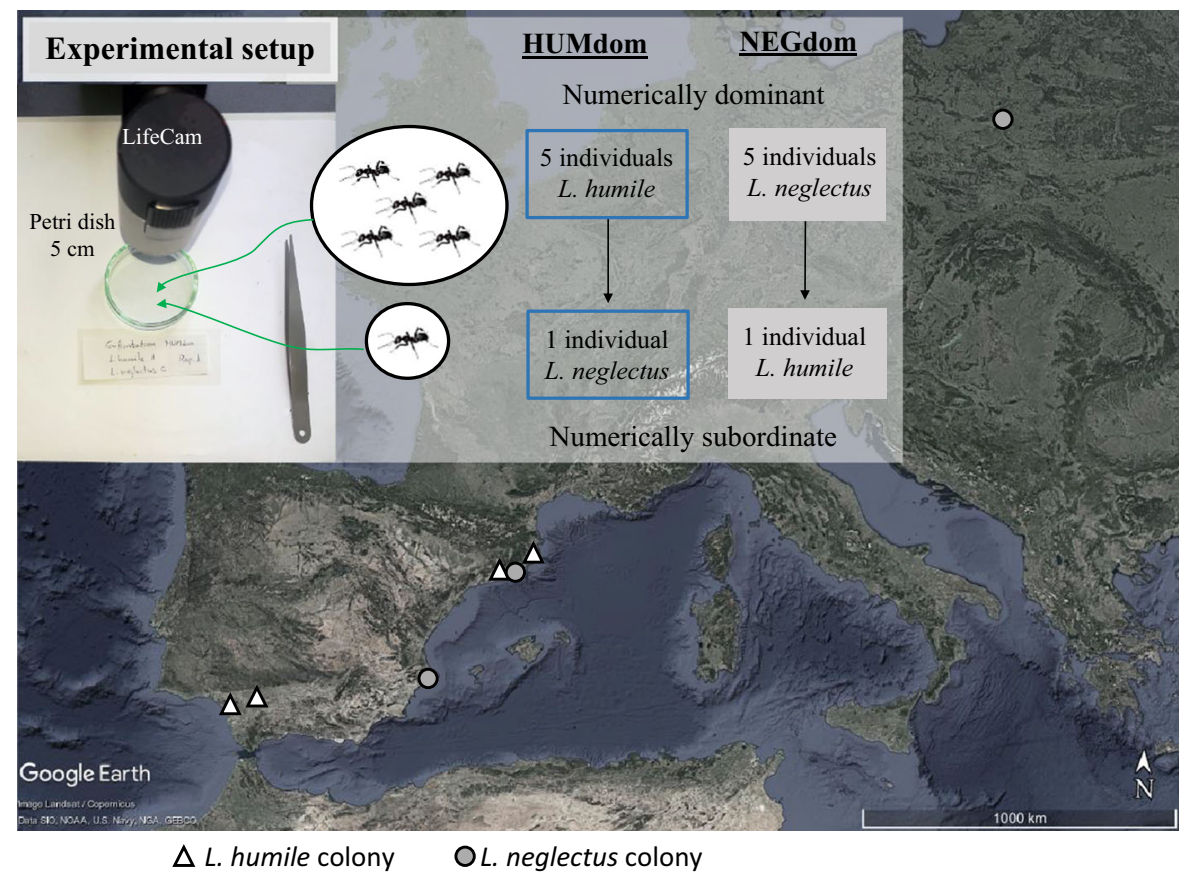

Fig. 1 Map of the locations where the colonies were collected and schematic representation of the experimental set-up. Source of map: Google Earth Pro v. 7.3.2.5776. (December 14, 2015). http://www.earth.google.com (image captured on January 3, 2020) 
numerically dominant (NEGdom: 5 L. neglectus vs. 1 L. humile) (Fig. 1).

The confrontations took place in Petri dishes (diameter: $5 \mathrm{~cm}$ ) whose sides had been coated with Teflon Fluon to prevent the ants from escaping. Ants were gently transported straight from their lab colonies to a Petri dish. The five numerically dominant ants were placed in the dish first and left there for 2 min to acclimatize; the numerically subordinate ant was then added, simulating the arrival of a competitor in an already colonized area. Each confrontation type (HUMdom and NEGdom) was repeated using different combinations of colonies, and each combination was repeated two times. A total of 48 confrontations were performed between the 4 colonies of $L$. humile and the 3 colonies of L. neglectus. There were 24 confrontations in which $L$. humile was numerically dominant (HUMdom: 12 combinations repeated twice) and 24 confrontations in which L. neglectus was numerically dominant (NEGdom: 12 combinations repeated twice). For each confrontation, we used new workers, which were removed from the colony afterwards. The confrontations were run for $5 \mathrm{~min}$, and a video recording was made of each using a camera (Microsoft LifeCam Studio Webcam) placed $20 \mathrm{~cm}$ above the Petri dish (Fig. 1). We then analyzed the videos using Behavioral Observation Research Interactive Software (BORIS; Friard et al. 2016), counting the number of times the ants performed different types of behaviors, which were categorized as either submissive or aggressive based on the results of previous studies of ant behavior (Maák et al. 2019, Scharf et al. 2011; Table S1).

\section{Statistical analyses}

All the statistical analyses were performed in $\mathrm{R}$ Statistical Environment (R Core Team 2019). GLMs and GLMMs were carried out using the glmer function in the lme 4 package (Poisson and binomial distributions; Bates et al. 2015) and the glmer.nb and glm.nb functions in the MASS package (negative binomial distribution; Venables and Ripley 2002). For each of the GLMs, we performed Tukey pairwise post hoc comparisons between colonies using the emmeans function in the emmeans package (Russell 2019). We plotted our results using the ggplot function in the ggplot 2 package (Wickham 2016) and the grid.arrange function in the gridExtra package (Auguie
2017). Count data were analyzed using the Poisson distribution, except when the residuals were overdispersed. In those cases, we used the negative binomial distribution instead. Proportions were analyzed using the binomial distribution.

Testing differences in aggressiveness between species

We examined differences in how each species behaved during the two confrontation types (i.e., when numerically dominant versus numerically subordinate).

First, we examined the aggressive behavior displayed by the numerically subordinate ants during the two confrontation types using a generalized linear mixed-effects model (GLMM; Poisson distribution, fit by maximum likelihood). The dependent variable was the number of times the numerically subordinate ant displayed an aggressive behavior; confrontation type (HUMdom vs NEGdom) was a fixed factor; and colony identity was a random factor (to account for colony-related variability).

Second, we examined the aggressive behavior displayed by the numerically dominant ants during the two confrontation types. Not all the numerically dominant ants actively participated in the confrontations ( $\%$ of confrontations with a given number of active numerically dominant ants: two-23.4\%, three-29.8\%, four $-31.9 \%$, and five- $14.9 \%$ ). Consequently, we analyzed that data using a GLMM with a binomial distribution: the dependent variable was the proportion of behaviors that were aggressive per active numerically dominant ant in each confrontation (calculated with the function cbind); confrontation type was a fixed factor; and colony identity was a random factor.

Testing differences in the behaviors and behavioral sequences of numerically subordinate ants

We examined differences in how each species behaved during the two types of confrontations (i.e., when numerically dominant versus numerically subordinate).

First, we examined differences in the behaviors (i.e., antennation, fleeing, mandible opening, biting, prolonged biting, and chemical attack) displayed by the numerically subordinate ant during the two 
confrontation types using GLMMs (Poisson distribution, fit by maximum likelihood). The behavior thanatosis was excluded because of its rarity. We performed separate models for each behavior: the dependent variable was the number of times a behavior was performed; confrontation type was a fixed factor; and colony identity was a random factor.

Second, the same series of models was performed to examine the number of times the active numerically dominant ants displayed each behavior. However, in these models, the random factor was the number of the repetition nested in colony identity.

Finally, we looked at the relative frequency of different behavioral sequences and transitions for each species in confrontations where the species was numerically subordinate. Behavioral strings were extracted from BORIS, and Behatrix was used to build a flow diagram for each species.

Testing the relationship between aggressiveness and numerical dominance

We were interested in determining whether the aggressiveness displayed by each species depended on its numerical dominance during the confrontation. We examined such differences in aggressiveness using GLMs (negative binomial distribution); there was one GLM per species. The dependent variable was the number of times an ant displayed an aggressive behavior (either the numerically subordinate ant or the most aggressive of the five numerically dominant ants, depending on confrontation type), and confrontation type was a fixed factor.

Testing the relationships between aggressiveness, colony identity, and ant role

We were interested in determining whether aggressiveness could be influenced by other factors, such as colony identity and the confrontational role played by ants from a given colony.

First, we looked differences in aggressiveness among colonies of the same species using generalized linear models (GLMs; Poisson distribution, fit by maximum likelihood). We ran four models: one with data from numerically subordinate $L$. humile ants, one with data from numerically subordinate $L$. neglectus ants, one with data from numerically dominant $L$. humile ants, and one with data from numerically dominant $L$. neglectus ants. The dependent variable was the number of times an ant displayed aggressive behavior, and colony identity was a fixed factor. In the models focused on the numerically dominant ants, we used the data for the most aggressive numerically dominant ant. To test for general differences among colonies, we carried out a Chi-squared test for each GLM using the anova function.

Second, we explored whether a colony's workers differed in their aggressiveness based on whether they were numerically subordinate or numerically dominant (GLM; negative binomial distribution). The dependent variable was the number of times the numerically subordinate ant or the most aggressive numerically dominant ant displayed aggressive behavior, and the ant's role (numerically subordinate or numerically dominant) was a fixed factor. We ran seven separate models: one for each colony of every ant species.

Testing the relationship between aggressiveness and species co-occurrence

We examined whether species co-occurrence affected aggressiveness. We were specifically interested in knowing whether ants from L. humile and L. neglectus colonies collected in Sant Cugat reacted differently to ants from colonies collected in areas where the species did not co-occur. We used four separate GLMs (Poisson distribution, fit by maximum likelihood) as described above (i.e., using data from numerically subordinate versus numerically dominant ants for each species). The dependent variable was the number of times the numerically subordinate ant or the most aggressive numerically dominant ant displayed aggressive behavior, and the presence/absence of species co-occurrence at a colony's area of origin was a fixed factor.

\section{Results}

Were there species-specific differences in the aggressiveness of the numerically subordinate ant?

The frequency of aggressive behavior by numerically subordinate ants differed significantly based on species. When each of the species was numerically 
subordinate, L. neglectus more frequently displayed aggressive behavior than did L. humile $(\mathrm{z}=-4.41$, $p<0.001$; Fig. 2a). There was no species-specific difference in aggressiveness in numerically dominant ants $(\mathrm{z}=-1.63, p=0.08$; Fig. $2 \mathrm{~b})$.

The type of behavior displayed by numerically subordinate ants also differed based on species. When each species was numerically subordinate, L. humile engaged less frequently in behaviors such as antennation, biting, mandible opening, or chemical attacks than $\operatorname{did}$ L. neglectus; however, L. humile's tendency to flee was significantly greater when it was the numerically subordinate ant (Fig. 3a). When each species was numerically dominant, $L$. humile less frequently engaged in fleeing, mandible opening, and chemical attacks than did L. neglectus; no significant differences were found for the other behavior categories (Fig. 3b).

Were there species-specific differences in behavioral sequences?

There were species-specific differences in the behavioral sequences displayed by the numerically subordinate ants. The most common behavioral sequence displayed by L. neglectus was more aggressive than the one displayed by L. humile. The Argentine ant was more inclined to start and finish confrontations with submissive behaviors whereas L. neglectus tended to keep up a high level of aggressiveness during the whole confrontation. In L . humile, the submissive behavior antennation was the first and most common behavior displayed by the ant. Antennation was followed by mandible opening in 39\% of confrontations and by a second instance of antennation in $30 \%$ of confrontations. In $L$. neglectus, the repetition of antennation was much less common (19\% of confrontations). Instead, antennation was followed by mandible opening and chemical attacks in $44 \%$ and $11 \%$ of confrontations, respectively. This sequence was slightly less common in L. humile (40\% and $8 \%$ of confrontations, respectively). The Argentine ant tended to follow one instance of mandible opening with a second (40\% of the confrontations) or with fleeing ( $16 \%$ of confrontations). In contrast, $L$. neglectus tended to start confrontations more aggressively (two sequential instances of mandible opening in $42 \%$ of confrontations). This behavioral sequence was generally followed up by either biting (15\% of confrontations) or a third instance of mandible opening (30\% of the confrontations). In L. humile, the most aggressive behavior-chemical attack-was followed by a second chemical attack in just $14 \%$ of confrontations; in L. neglectus, this percentage was much higher: $23 \%$. Finally, the most submissive behavior, thanatosis, was only performed by $L$. humile; it was never displayed by L. neglectus (Fig. 4a, b).

Were there species-specific differences in the aggressiveness of the numerically dominant ant?

There were species-specific differences in aggressiveness when ants were numerically dominant. Regardless of whether L. humile was numerically subordinate or dominant, its frequency of aggressive behaviors did not differ (Fig. 5a). In contrast, when L. neglectus was numerically subordinate, it more frequently displayed aggressive behaviors than when it was numerically dominant (Fig. 5b).

Were there relationships between aggressiveness, colony identity, and ant role?

Species displayed colony-specific differences in behavior both when numerically subordinate and numerically dominant (Chi-square test-L. humile: numerically subordinate: $\chi^{2}=42.44, \quad d f=3$, $p<0.0001$, numerically dominant: $\chi^{2}=118.98$, $d f=3, p<0.0001 ;$ L. neglectus: numerically subordinate: $\chi^{2}=38.77, d f=2, p<0.0001$, numerically dominant: $\left.\chi^{2}=62.02, d f=2 ; p<0.0001\right)$. However, the pairwise comparisons indicated that there were significant differences between some of the colonies. When L. humile was numerically subordinate, the Sant Cugat colony (representing the Catalan supercolony) was more aggressive than the Doñana and Girona colonies (both representing the Main supercolony) ( $p \leq 0.003$ in both cases) but was not significantly different from the Seville colony (Fig. 6a, Table S2). By contrast, when L. neglectus was numerically subordinate, the Sant Cugat colony was less aggressive than the Gandía and Warsaw colonies ( $p$ $\leq 0.0001$ in both cases, Fig. 6 b, Table S2). When $L$. humile was numerically dominant, the Sant Cugat colony behaved the least aggressively $(p<0.001$, Fig. 6c, Table S2); when L. neglectus was numerically dominant, the opposite was true: the Sant Cugat 
colony was the most aggressive $(p \leq 0.001$, Fig. $6 \mathrm{~d}$, Table S2).

Ants from different colonies behaved differently depending on their role in the confrontations (numerically subordinate vs. numerically dominant). In the case of L. humile, ants from the Sant Cugat colony were more aggressive when they were numerically dominant. By contrast, in L. neglectus, ants from the Sant Cugat colony were more aggressive when they were numerically subordinate (Fig. 7a, b, Table S3). In L. humile, ants from the Doñana colony were more aggressive when they were numerically subordinate (Fig. 7e, Table S3); however, the Seville and Girona colonies showed no such differences (Fig. 7c, g, Table S3). In L. neglectus, ants from Gandía, Warsaw, and Sant Cugat colonies were more aggressive when they were numerically subordinate (Fig. 7d, f, Table S3).

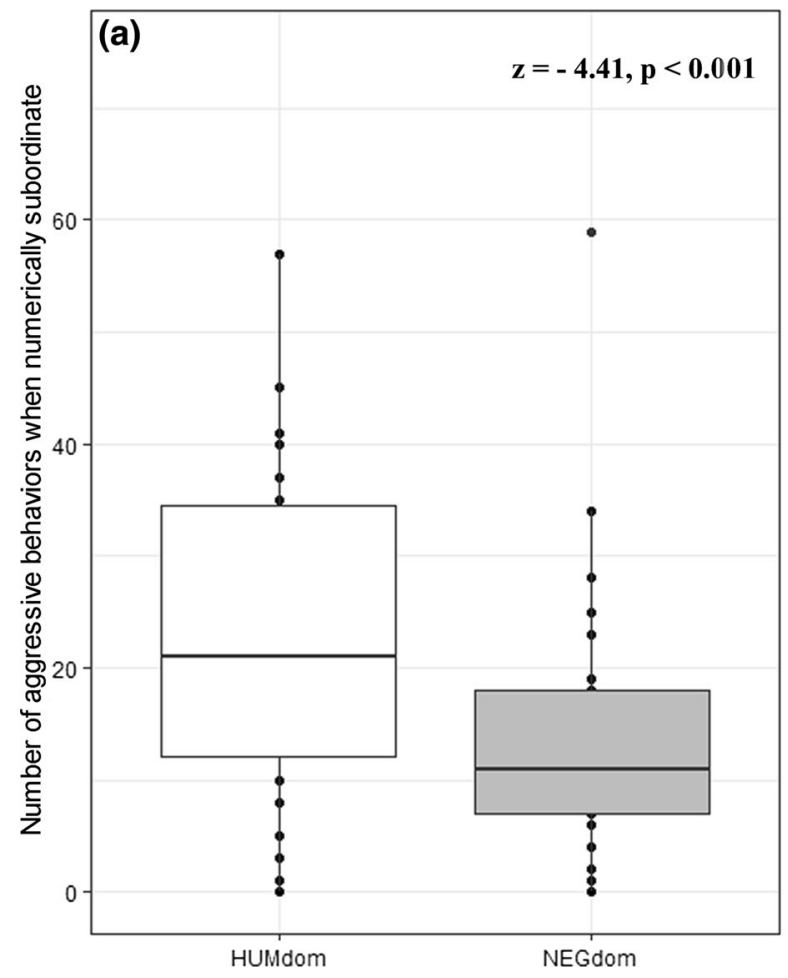

Fig. 2 Frequency of aggressive behaviors displayed by a numerically subordinate and $\mathbf{b}$ numerically dominant ants during the two confrontation types (HUMdom: L. humile was numerically dominant; NEGdom: L. neglectus was numerically
Fig. 3 Frequency of the different behavior types displayed by a the numerically subordinate ant $(\mathrm{n}=24)$ and $\mathbf{b}$ the numerically dominant ants $(\mathrm{n}=24)$ during the two confrontation types (HUMdom $=L$. humile was numerically dominant; NEGdom $=$ L. neglectus was numerically dominant). The statistical results are at the top of each graph; they are in bold when significant. The boxplots show the median, upper and lower quartiles, minimum and maximum, and any outliers

Was there a relationship between aggressiveness and species co-occurrence?

When we specifically examined how species cooccurrence affected aggressiveness, we found that numerically dominant $L$. humile ants from Sant Cugat were significantly less aggressive toward numerically subordinate L. neglectus ants from Sant Cugat versus from other colonies (Fig. 8c); however, no such difference was found when $L$. humile was numerically subordinate (Fig. 8a). Moreover, numerically subordinate L. neglectus ants from Sant Cugat behaved

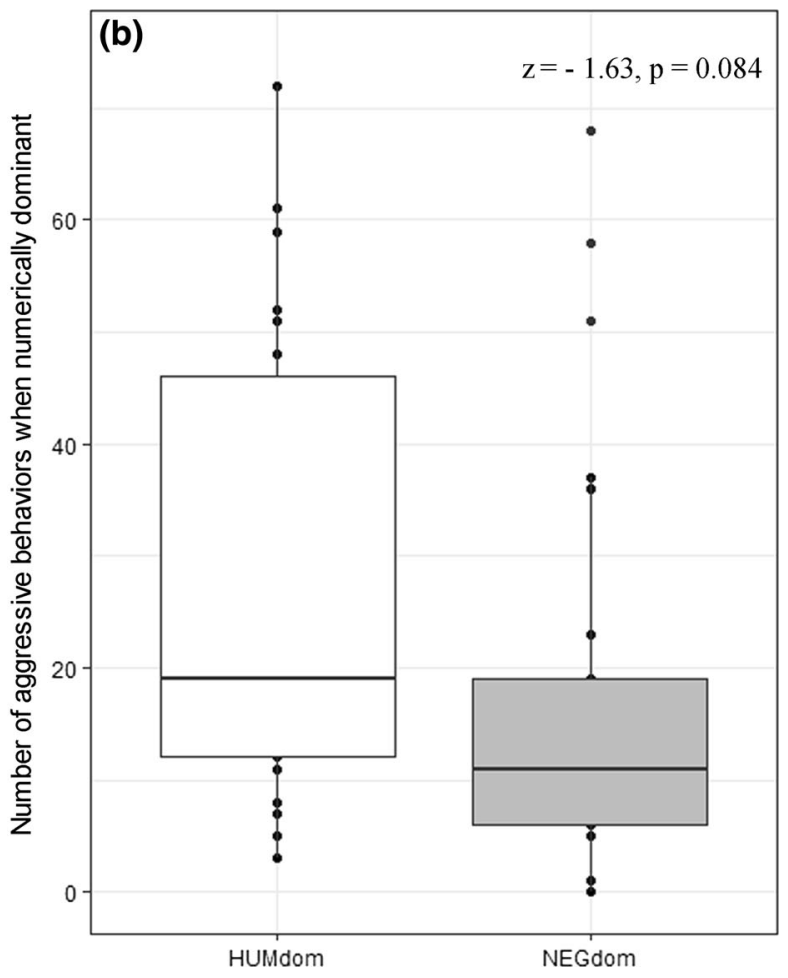

dominant; $n=24$ ). The statistical results are at the top of each graph; they are in bold when significant. The boxplots show the median, upper and lower quartiles, minimum and maximum, and any outliers 
(a) Frequency of behaviors of the numerically subordinate ant
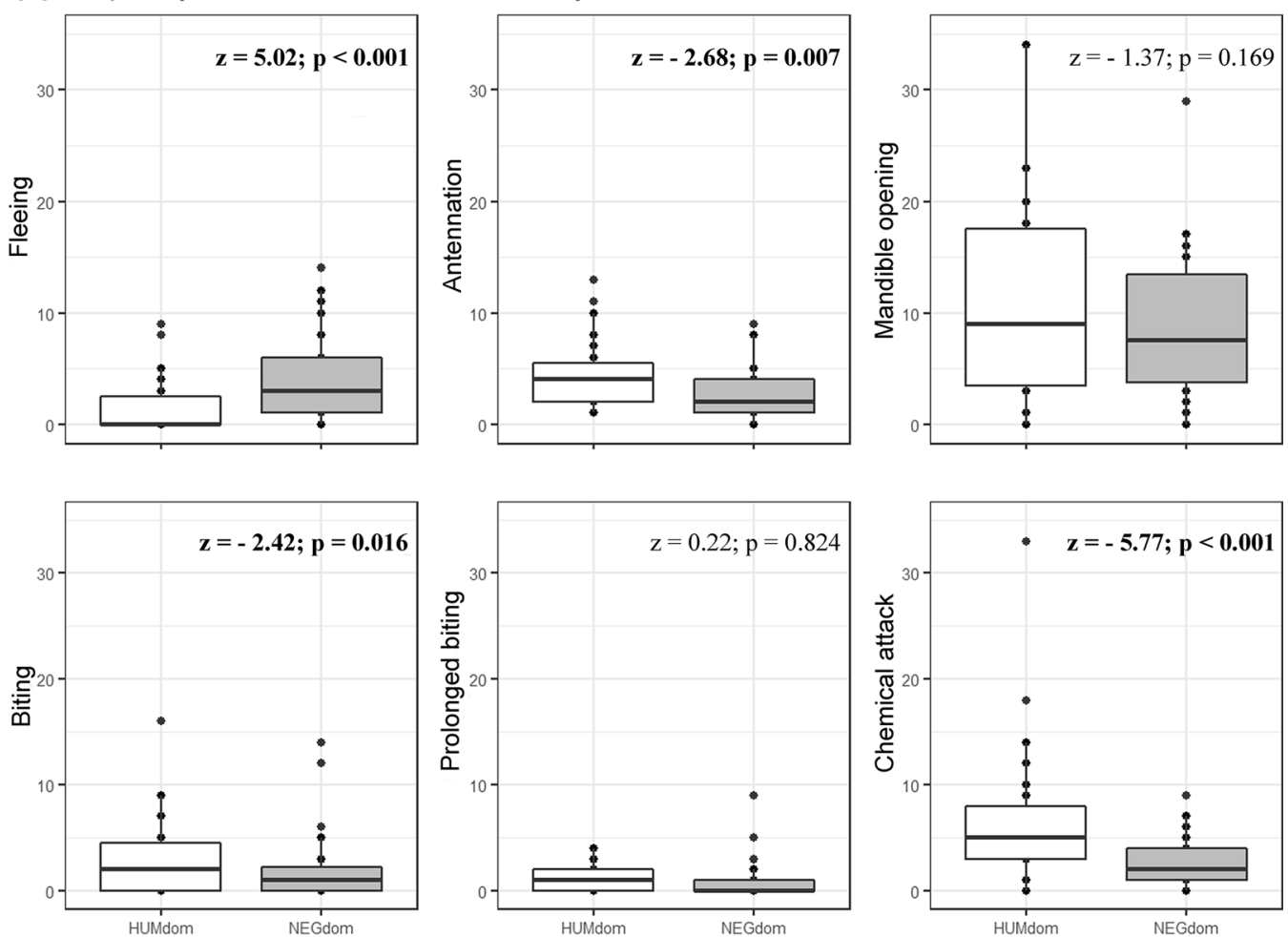

(b) Frequency of behaviors of the numerically dominant ant
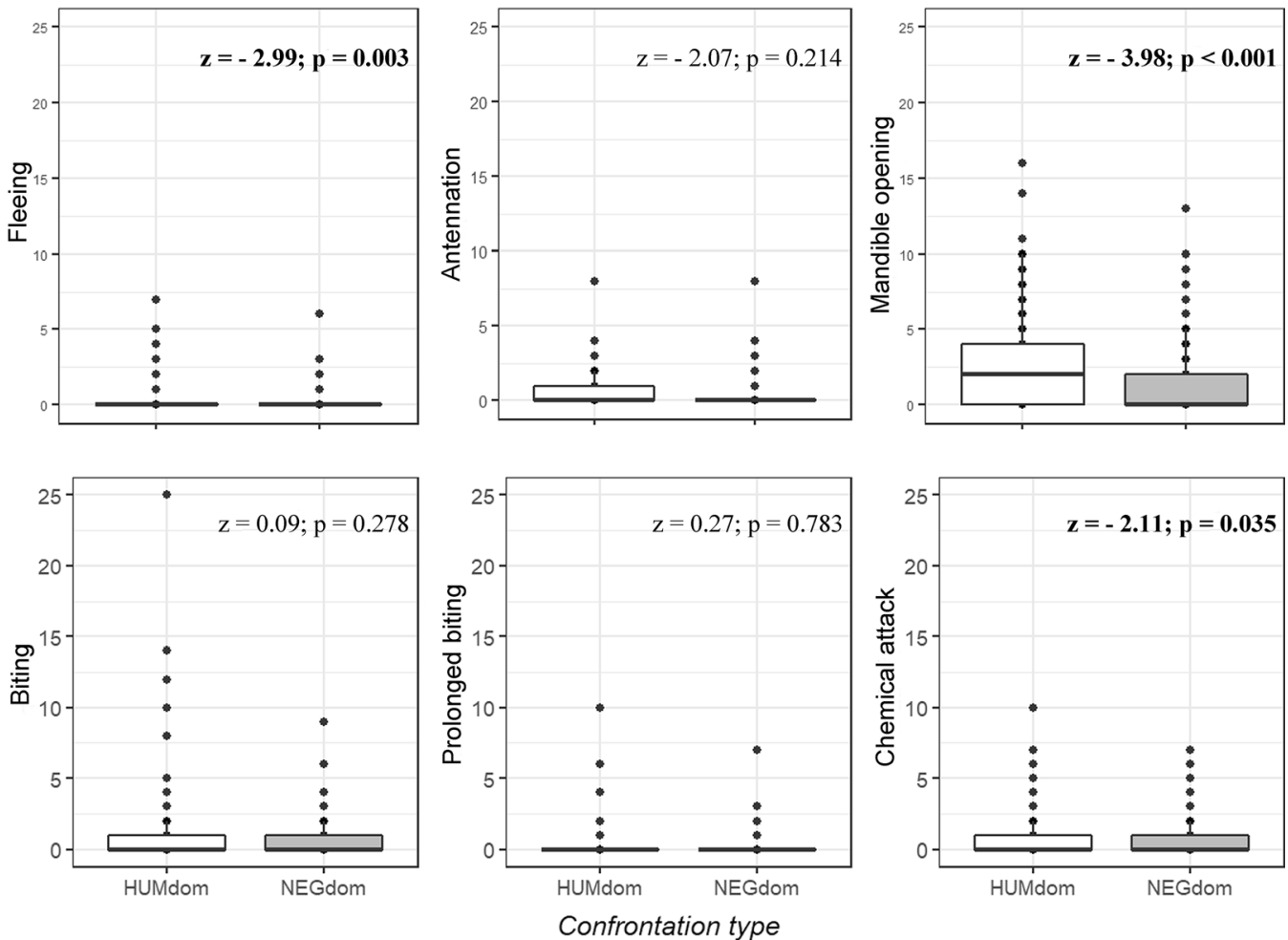
(a) Sequence of behaviors of Linepithema humile

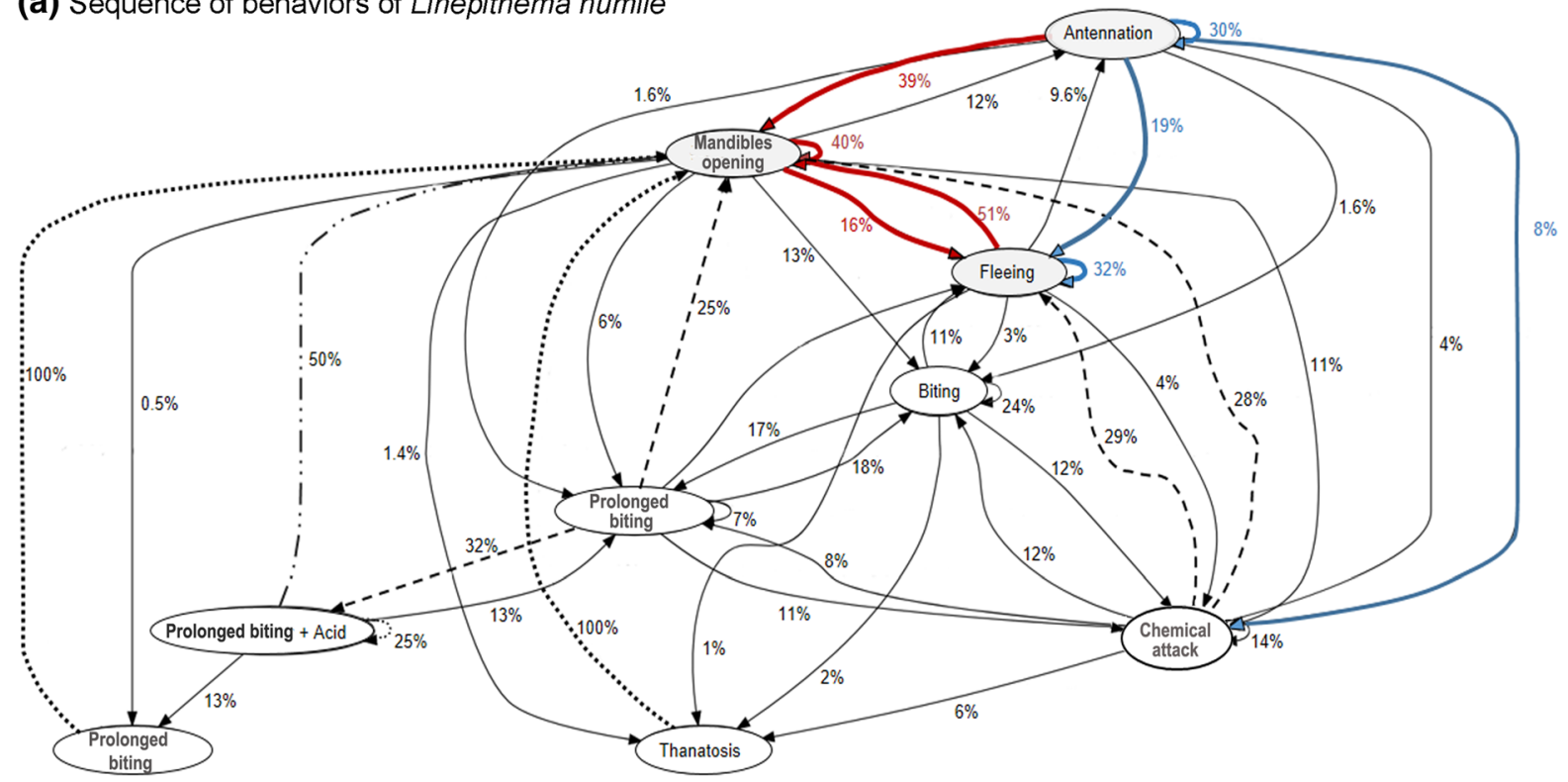

(b) Sequence of behaviors of Lasius neglectus

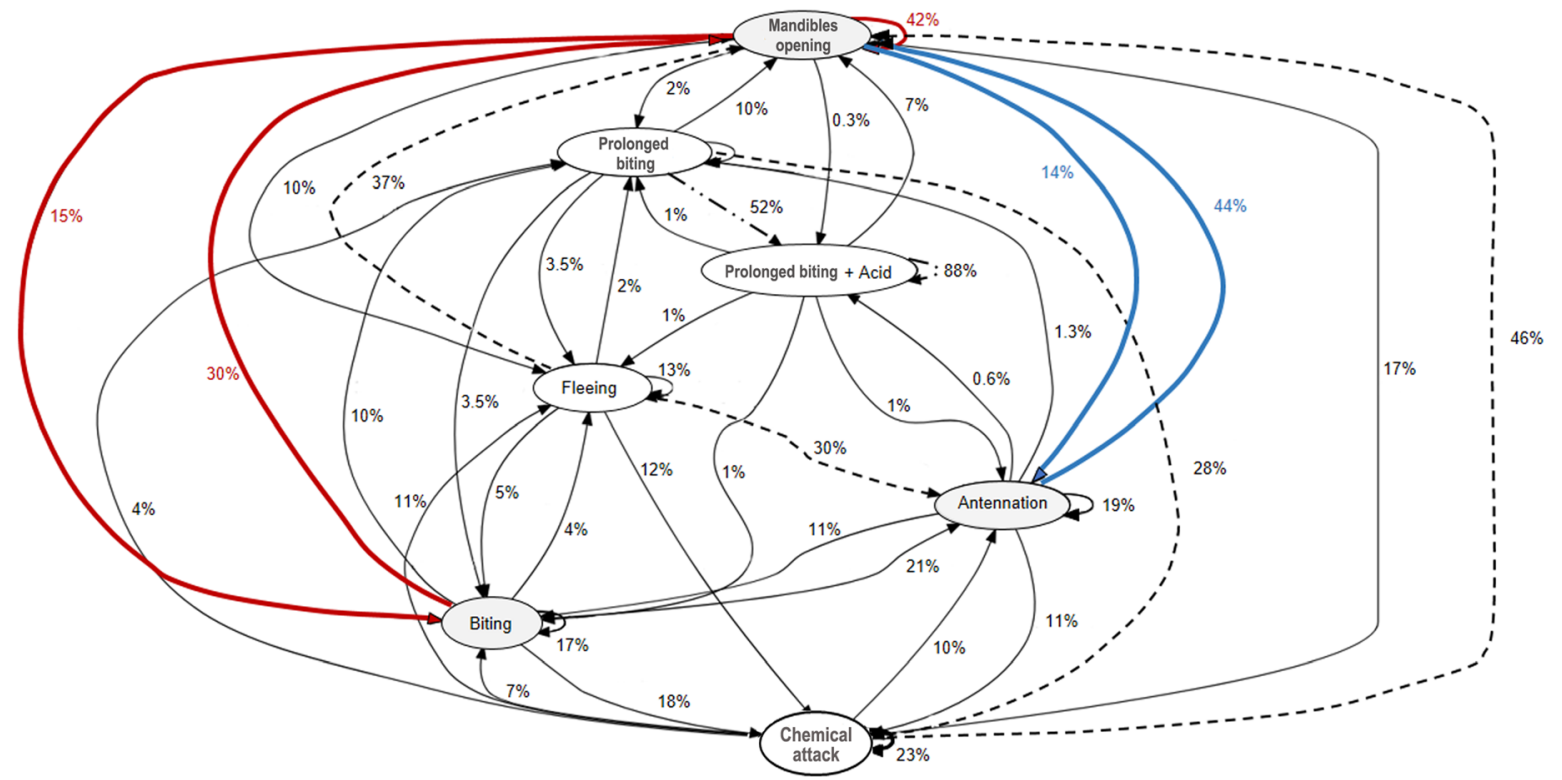

Fig. 4 Schematic representation of the behavioral sequences of a L. humile and $\mathbf{b}$ L. neglectus when acting as numerically subordinate ants. The most common behavioral sequences are in red; the second most common behavioral sequences are in blue.

significantly more aggressively toward numerically dominant $L$. humile ants from Sant Cugat versus from other colonies (Fig. 8b); no significant differences were found when L. neglectus was numerically dominant (Fig. 8d).
Line type indicates the relative frequency of the transitions: dotted lines-100\%; striped lines-50\% < relative frequency $<100 \%$; striped + dotted lines $-25 \% \leq$ relative frequency $<50 \%$; and solid lines $-<25 \%$

\section{Discussion}

Two highly invasive ant species, $L$. humile and $L$. neglectus, are expanding their ranges in Europe and thus constitute one of the main threats to the 
(a) Linepithema humile

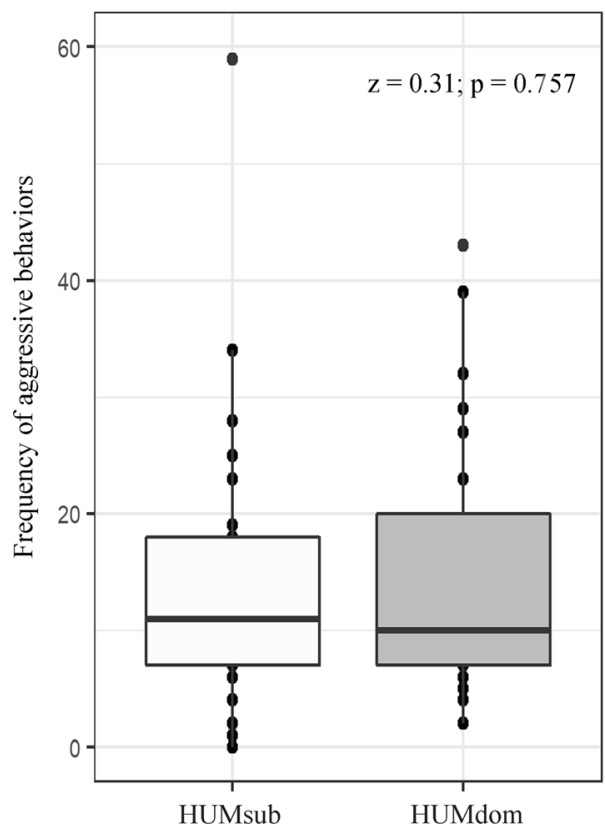

Fig. 5 Frequency of aggressive behaviors displayed by a $L$. humile and $\mathbf{b}$ L. neglectus when numerically subordinate versus numerically dominant $(\mathrm{n}=24$ trials for each confrontation type for each species). The statistical results are at the top of each

continent's native biodiversity (Gómez et al. 2003; Gómez and Oliveras 2003; Blancafort and Gómez 2006; Angulo et al. 2007; Nagy et al. 2009; Abril and Gómez 2011). The two species have similar ecologies and thus their ranges could potentially overlap; they might even end up co-occurring in many areas, as they already do in Sant Cugat, Spain. Linepithema humile arrived in Europe before L. neglectus, but the latter dominates the former in confrontations involving equal numbers of ants (Bertelsmeier et al. 2015c). Consequently, we wished to test the effect of numerical dominance on their interactions. Our results show that $L$. neglectus remained behaviorally dominant and highly aggressive even when it was numerically subordinate to L. humile. However, in interactions involving ants from Sant Cugat, where the species cooccur, L. humile but not L. neglectus, seemed to employ the dear-enemy strategy, reducing in part the level of aggressiveness during confrontations. Thus, our study describes how L. humile and L. neglectus can modulate their behaviors, and the background mechanisms that can facilitate the co-occurrence of these two highly aggressive invasive species. (b) Lasius neglectus

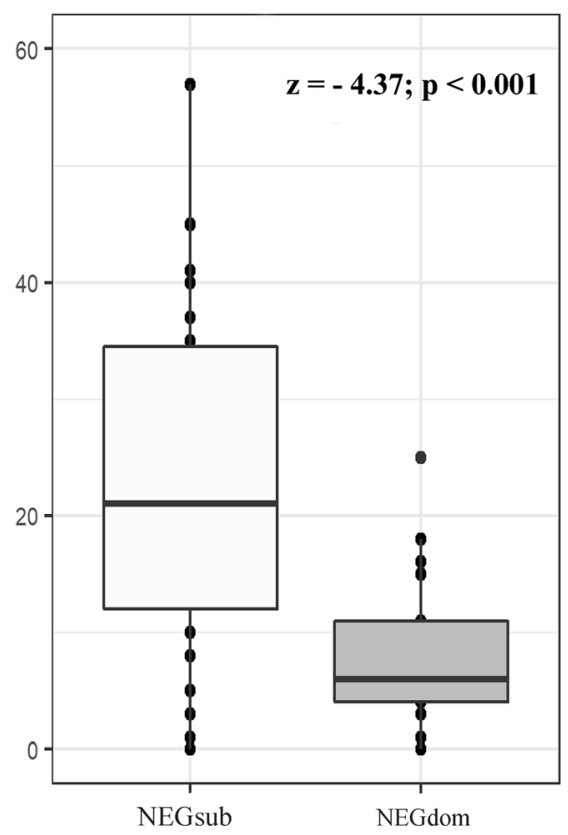

graph; they are in bold when significant. The boxplots show the median, upper and lower quartiles, minimum and maximum, and any outliers

Aggressiveness and numerical dominance: the Bourgeois strategy

Invasive ants share a series of ecological and biological traits, which are often collectively called the "invasive syndrome" (Passera 1994). These traits facilitate their success during invasions (Bertelsmeier et al. 2017; Fournier et al. 2017). However, these similarities may also result in invasive species competing for the same resources when they co-occur, with competitive displacement as the final outcome. Indeed, several studies have observed the invasion treadmill phenomenon, where two invasive ant species initially co-occur but later one displaces the other (Thomas and Reid 2007; LeBrun et al. 2007; Krushelnycky and Gillespie 2010; Spicer Rice and Silverman 2013). However, the invasive syndrome does not imply that all invasive ant species display equal levels of aggressiveness; instead, they are organized into a dominance hierarchy (Bertelsmeier et al. 2015a). However, the linear hierarchy established by Bertelsmeier et al. (2015a) was based on species confrontations involving similar numbers of competitors. The results may have differed if competitor number 


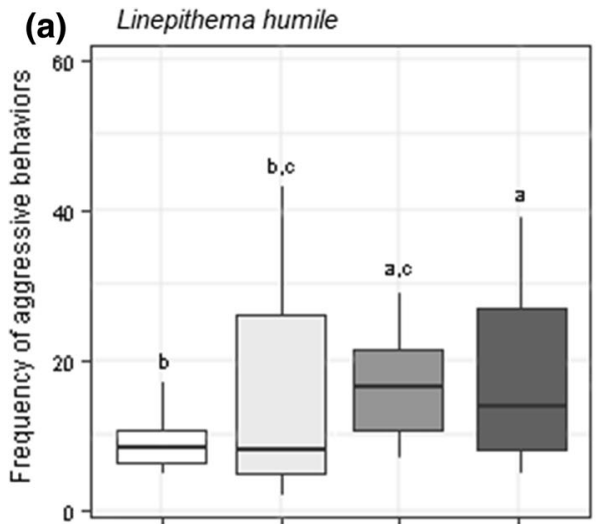

(b) Lasius neglectus
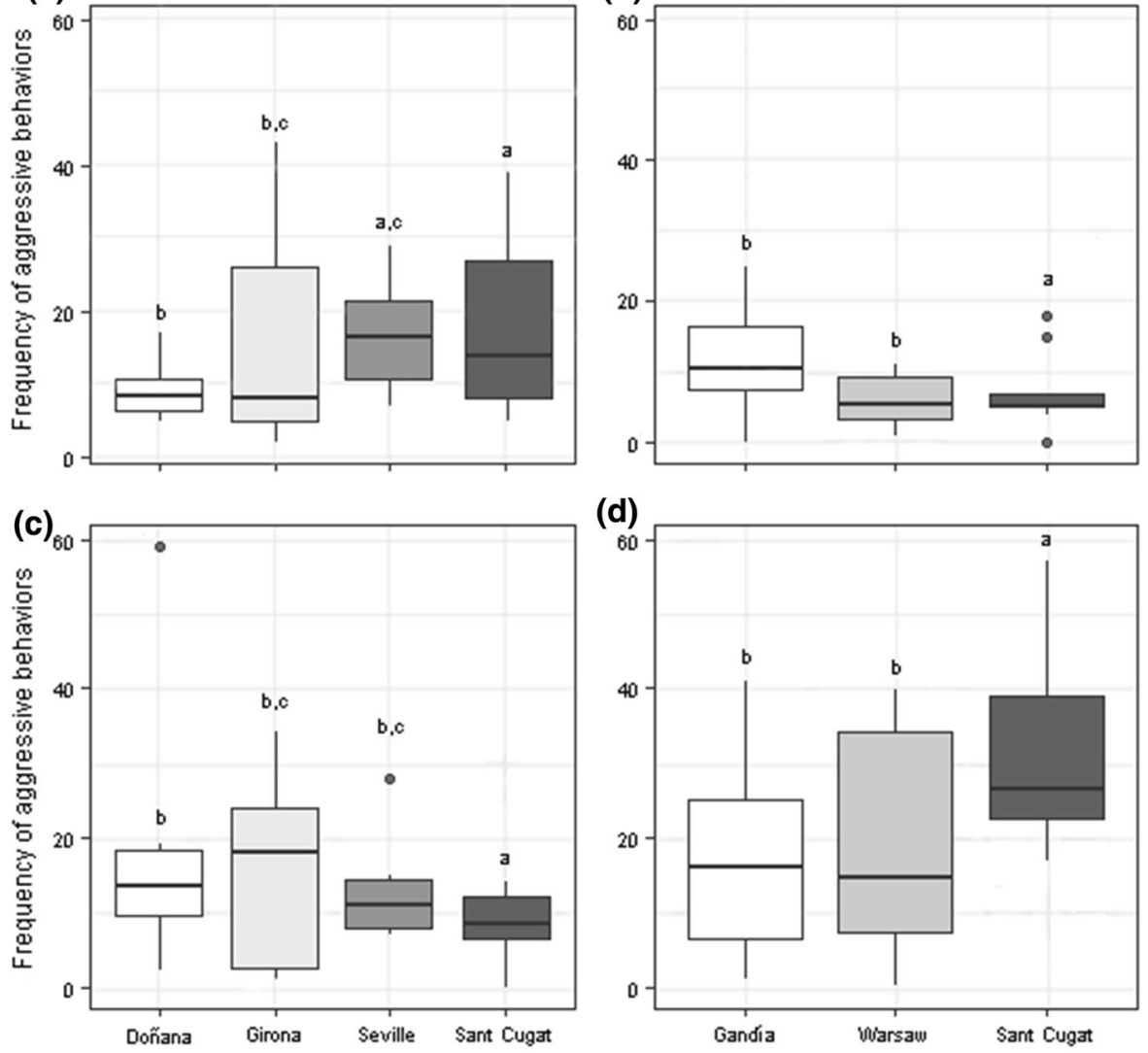

(d)

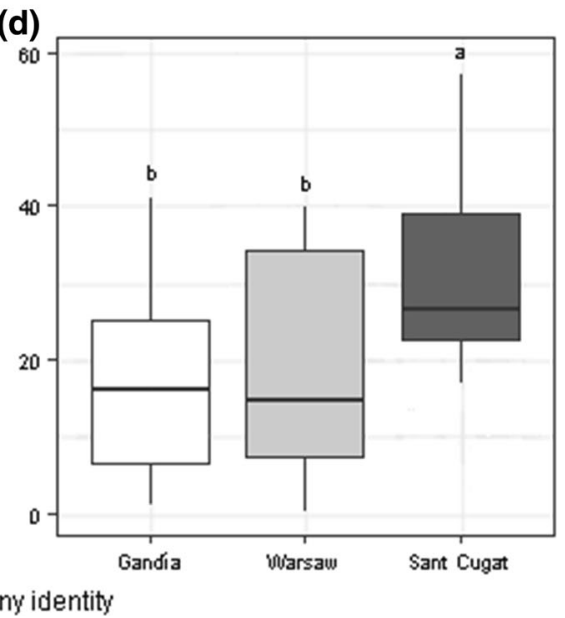

Fig. 6 Frequency of aggressive behaviors displayed by ants from different colonies of numerically subordinate a $L$. humile and $\mathbf{b} L$. neglectus and of numerically dominant $\mathbf{c} L$. humile and d L. neglectus $(\mathrm{n}=12$ trials for each confrontation type for each colony of each species). In $\mathbf{c}, \mathbf{d}$ the data came from the most

had been unequal. In our study, we observed that $L$. neglectus displayed a consistent level of aggressiveness: ants from all the colonies were always more aggressive in confrontations with L. humile when they were numerically subordinate. This pattern was seen in both the higher number of aggressive interactions and the type of behaviors exhibited: L. neglectus employed more aggressive behaviors, such as biting or chemical attacks, while L. humile mostly performed submissive behaviors, such as fleeing or thanatosis. These results concur with those of Cremer et al. (2006), who showed that the invasive L. neglectus displayed a higher frequency of aggressive behaviors, notably biting and chemical attacks, than did native Lasius species.

aggressive of the numerically dominant ants. The boxplots show the median, upper and lower quartiles, the minimum and maximum, and any outliers; boxes with the same letter were not statistically different

However, aggressiveness is defined by more than just the frequency of aggressive behaviors; it is also the sequence in which behaviors are performed. For example, if an ant progressively uses more aggressive behavior, a confrontation can become more violent. In our study, L. neglectus was not only more frequently aggressive, it also employed increasingly aggressive behavioral types. Like Bertelsmeier et al. (2015a, 2016), we found that L. neglectus has better competitive skills than $L$. humile, even if the latter displays numerical dominance. Indeed, when arriving in an area already colonized by L. humile, L. neglectus can utilize this advantage to better compete for resources, allowing it to occupy a higher position in the dominance hierarchy (Bertelsmeier et al. 2015a, 2016). 
It is also important to note that competition strategies may be flexible and can shift to increase the probability of success (Suárez et al. 1999). The particular strategy employed during interspecific conflicts depends on different factors, such as competitor abundance and aggressiveness; environmental conditions; social conditions; and the duration of the interaction (DiGirolamo and Fox 2006; Frizzi et al. 2017; Abril and Gómez 2009; Blight et al. 2010; Kleineidam et al. 2017). Indeed, in ant species, competitor abundance and aggressiveness play a key role in interspecific interactions and may vary in order to boost competitive ability. For example, it has been shown that $L$. humile and some native Mediterranean ant species altered their behavior based on the number of conspecifics present on baits, thus adopting the Bourgeois strategy (Carpintero and Reyes-López 2008). Indeed, native and exotic species all around the world use the Bourgeois strategy to expulse other species and monopolize resources using aggressive behaviors (Holway and Suárez 1999; Drescher et al. 2010). Here, we found that $L$. humile used the Bourgeois strategy in confrontations with L. neglectus. When L. humile was numerically subordinate, it displayed more submissive behaviors, such as thanatosis or fleeing. However, when it was numerically dominant, it displayed a greater frequency of aggressive behaviors. Interestingly, Blight et al. (2010) also observed that $L$. humile workers engaged in thanatosis when they were losing confrontations. This submissive behavior has also been observed in Plagiolepis pygmaea in confrontations with L. humile, and it may greatly contribute to the co-occurrence of these two species in the Mediterranean (Abril and Gómez 2009).

Aggressiveness and co-occurrence: the dearenemy hypothesis

Behavioral interactions among ant species are affected not only by behavioral dominance or numerical dominance but also by colony personality (Carere et al. 2018; Blight et al. 2017). Indeed, behavior and competitive ability can vary among colonies of the same species. For example, in L. humile in Europe, ants from the Main supercolony were found to be more aggressive and to more readily explore novel environments than ants from the Catalan supercolony (Abril and Gómez 2011; Blight et al. 2017). The results of our study support these previous findings
(Abril and Gómez 2011) because, when L. humile was numerically subordinate, ants from the Catalan supercolony (Sant Cugat) were less aggressive than ants from the Main supercolony (Doñana and Girona).

The behavioral plasticity displayed by L. humile in response to local conditions probably facilitates invasion success (Holway and Suárez 1999; Sagata and Lester 2009) and can therefore shape the outcome of situations in which $L$. humile co-occurs with another invasive species, such as L. neglectus. When we staged confrontations between ants taken from an area where L. humile and L. neglectus co-occur (Sant Cugat), we observed that numerically dominant $L$. humile ants were less aggressive toward numerically subordinate L. neglectus ants than when the confrontations involved ants from areas where there is no species co-occurrence. We found similar results for $L$. neglectus: numerically subordinate $L$. neglectus ants were less aggressive toward familiar versus foreign numerically dominant $L$. humile ants. This finding suggests the dear-enemy strategy may facilitate the cooccurrence of these two invasive ant species in this particular area. Our results also support the idea that $L$. humile can use its behavioral plasticity to persist in the presence of $L$. neglectus, despite the latter's greater aggressiveness and better competitive skills. In their natural range, the coevolution of the different species lead to some of them to evolve a subordinate strategy towards the dominant species, an strategy also displayed in invaded areas as a result of their lifehistory tradeoff (Morrison 1996). For example, part of the invasion success of $L$. humile could be related with escaping from coevolved natural enemies (Holway and Suárez 1999), as it is the case with L. neglectus in San Cugat. This shift in behavior could be the underlying cause of the dear-enemy phenomenon that was observed. This phenomenon (Fisher 1954) is common in social insects, and it has been previously described in other ant species (Heinze et al. 1996; Boulay et al. 2007; Grangier et al. 2007; Dimarco et al. 2010). Furthermore, L. humile has also been found to co-occur with other invasive species such as Cardiocondyla mauritanica (Gómez and Espadaler 2005) in Balearic Islands, and with Cardiocondyla obscurior and Tetramorium caldarium in Alicante and Andalusia (Trigos-Peral and Reyes-López 2016; Trigos-Peral et al. 2020). Consequently, it is possible that the above mentioned behavioral plasticity of L. humile may facilitate its co-occurrence with other invasive species. 


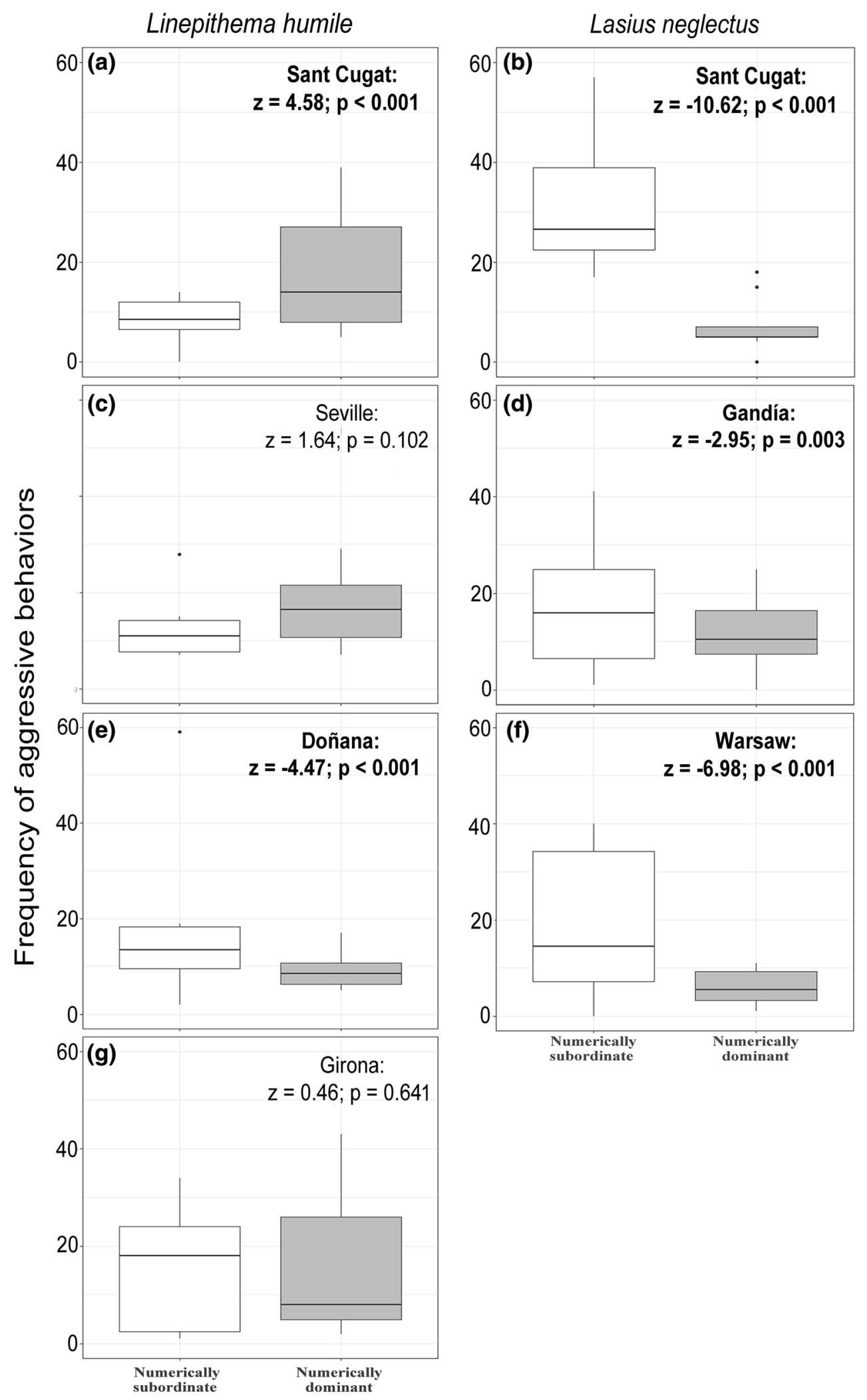


4Fig. 7 Frequency of aggressive behaviors displayed by numerically subordinate versus numerically dominant ants from different colonies of L. humile (a, c, e, g) and L. neglectus (b, d, f) $(n=12$ trials for each confrontation type for each colony of each species). The statistical results are at the top of each graph; they are in bold when significant. The boxplots show the median, upper and lower quartiles, minimum and maximum, and any outliers

\section{Study limitations and implications}

The competitive success of a given species is often determined by the suitability of local environmental conditions, species abundance, and species aggressiveness (Buczkowski and Bennett 2007; Blight et al. 2010; Bertelsmeier et al. 2015a, b; Frizzi et al. 2017). In our study, we assumed that environmental conditions played a secondary role since $L$. humile and L. neglectus share ecological similarities. However, because they come from different geographical areas (South America and the Anatolian Peninsula, respectively), local-scale environmental conditions in their invasive ranges might differentially affect their behavioral responses during confrontations in the field.

We also assumed that species abundance was correlated with species time of arrival. The first invasive species to arrive within a new area can become numerically dominant, increasing its likelihood of outcompeting a later-arriving species (Bang et al. 2017). Previous work has shown that only some cryptic native ant species remained in areas that $L$. humile had successfully invaded (and where its nests were larger and more numerous) while the native ant
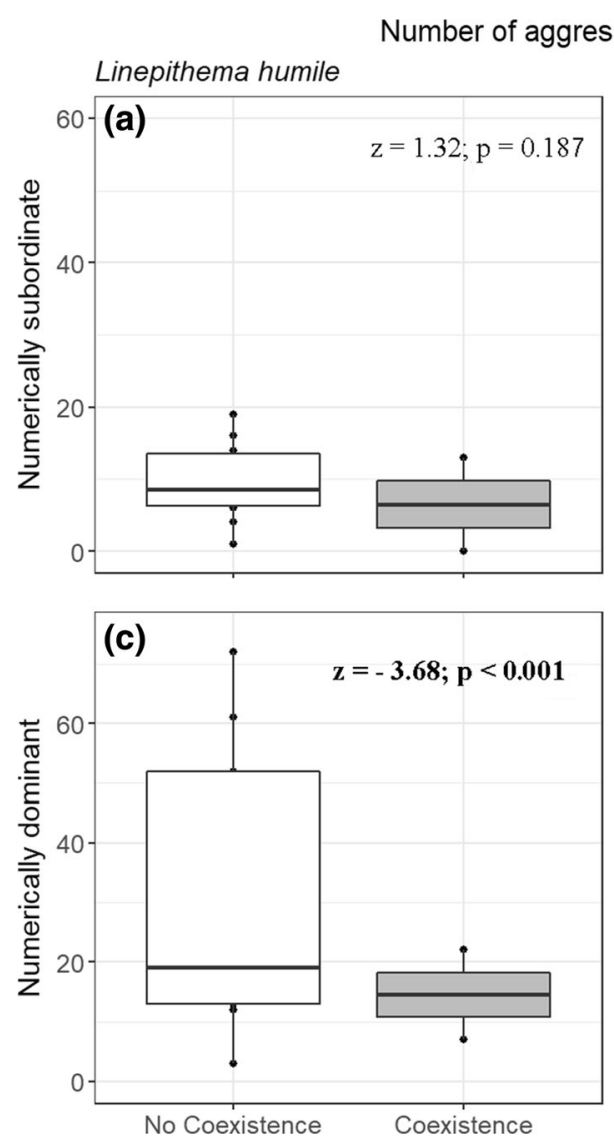

Fig. 8 Frequency of aggressive behaviors displayed by numerically subordinate a L. humile and $\mathbf{b} L$. neglectus and numerically dominant c $L$. humile and d L. neglectus in confrontations involving colonies from areas where the species did and did not co-occur $(\mathrm{n}=12$ trials for each confrontation

type for each species in each type of area). The statistical results are at the top of each graph; they are in bold when significant. The boxplots show the median, upper and lower quartiles,

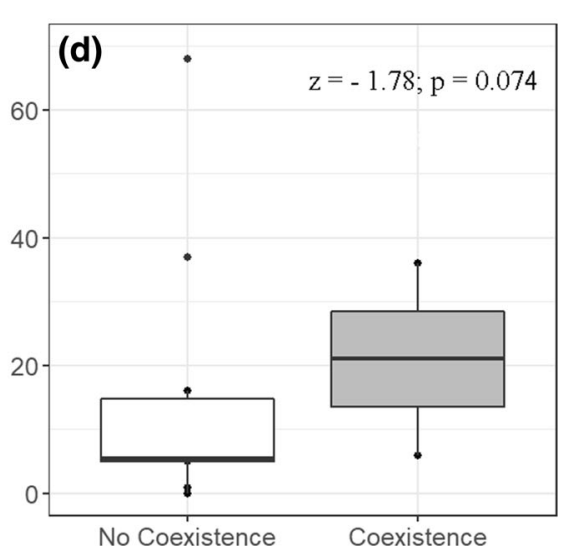

minimum and maximum, and any outliers

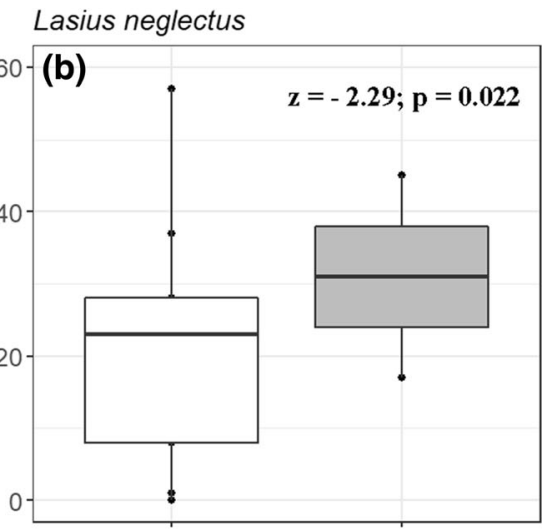


community still co-occurred with $L$. humile near the invasion front (Diaz et al. 2014).

Our study did not address certain other factors that might influence species behavior and that might be involved in the establishment and success of invasive species. For example, ants could not fully flee from the confrontations staged in our experimental trials. Since natural habitat complexity could strongly influence species' responses and promote co-occurrence (Gibb and Parr 2010; Sarty et al. 2006), our trials could have yielded very different results if carried out in the field; indeed, the dear-enemy effect might have been stronger.

That said, the controlled conditions of laboratory experiments make it possible to test whether species are specifically responding to the applied treatments (e.g., by excluding environmental variability). Laboratory experiments are especially useful in the field of invasion biology because they can be used as tools for predicting the possible outcomes of as-yet infrequent scenarios that are expected to become more common, such as the co-occurrence of the two invasive species L. humile and L. neglectus.

Additionally, temperature has been shown to be a key factor that mediates interspecific competition. Frizzi et al. (2017) found that the competitive ability of L. neglectus was lower at higher temperatures. This fact may give a competitive advantage to $L$. humile in the areas where these two species co-occur, given that L. humile is slightly better at tolerating higher temperatures and drier conditions (Jumbam et al. 2008). Global warming seems to be greatly enhancing habitat suitability for invasive species by increasing resource availability, decreasing the resistance of native communities to the establishment of invasive species, and giving invasive species a competitive advantage over already established non-native species (Diez et al. 2012). Thus, climate change may allow $L$. humile and L. neglectus to spread to colder parts of Europe (Roura-Pascual et al. 2004; Bertelsmeier and Courchamp 2014; Stukalyuk 2017). Indeed, current models exploring the distributions of invasive ant species under climate change conditions have predicted that these species will continue spreading as average global temperature increases (d'Ettorre and Lenoir 2010). Thus, interactions between temperature and ant numerical dominance merit further research.

Our study is the first to show how behavioral plasticity in L. humile may greatly facilitate the species' co-occurrence with other highly aggressive invasive species, such as L. neglectus. Because of global warming, the invasion of the same habitat by multiple species is a reality, and both the bourgeois and dear-enemy strategies may facilitate species establishment. Our results also highlight the importance of conducting future research exploring the potential of the invasive species to co-occur in base to their morphological traits, aggressiveness and behavioral plasticity; such work can help reveal how both factors affect native communities and environmental conservation.

Acknowledgements We thank Prof. Xavier Espadaler for helping us identify and locate the co-occurring colony fragments of the two study species, Javier Arcos for collecting the colony fragments from Gandía, Iga Wojciechowska for analyzing some of the video recordings, and Jessica Pearce for improving and editing the manuscript's English. We also want to thanks to all women that came before us and in whose shoulders we are to keep making science inclusive and equal opportunity. Any specific funding covered these experiments, only our desire to do science in spite of our precarious positions.

Open Access This article is licensed under a Creative Commons Attribution 4.0 International License, which permits use, sharing, adaptation, distribution and reproduction in any medium or format, as long as you give appropriate credit to the original author(s) and the source, provide a link to the Creative Commons licence, and indicate if changes were made. The images or other third party material in this article are included in the article's Creative Commons licence, unless indicated otherwise in a credit line to the material. If material is not included in the article's Creative Commons licence and your intended use is not permitted by statutory regulation or exceeds the permitted use, you will need to obtain permission directly from the copyright holder. To view a copy of this licence, visit http://creativecommons.org/licenses/by/4.0/.

\section{References}

Abellán P, Tella JL, Carrete M, Cardador L, Anadón JD (2017) Climate matching drives spread rate but not establishment success in recent unintentional bird introductions. Proc Nation Acad Sci 114(35):9385-9390

Abril S, Gómez C (2009) Ascertaining key factors behind the coexistence of the native ant species Plagiolepis pygmaea with the invasive argentine ant Linepithema humile (Hymenoptera: Formicidae). Sociobiology 53(2b):559-568

Abril S, Gómez C (2011) Aggressive behaviour of the two European Argentine ant supercolonies (Hymenoptera: Formicidae) towards displaced native ant species of the northeastern Iberian Peninsula. Myrmecol News 14:99-106 
Angulo E, Boulay R, Rodrigo A, Retana X, Cerdá X (2007) Efecto de una especie invasora, Linepithema humile, la hormiga argentina, sobre la biodiversidad del parque nacional de doñana (huelva): descripción de las interacciones con las hormigas nativas. Proyectos de investigación en parques nacionales: 2003-2006. L.Ramírez \& B.Asensio eds. OAPN, Ministerio Medio Ambiente, Madrid. ISBN: 978-84-8014-722-4

Auguie B (2017) gridExtra: miscellaneous functions for "Grid". Graphics. R package version 2.3. https://CRAN.R-project. org/package $=$ gridExtra

Axen HJ, Wildermuth A, Cahan SH (2014) Environmental filtering of foraging strategies mediates patterns of coexistence in the fire ants Solenopsis geminata and Solenopsis xyloni, and their interspecific hybrids. Ecol Entomol 39:290-299

Bang A, Luque GM, Courchamp F (2017) Live-in if you must: density-dependent nest-sharing between two competitive ant species. Curr Sci 112(8):1631-1632

Bates D, Maechler M, Bolker B, Walker S (2015) Fitting linear mixed-effects models using lme4. J Stat Softw 67(1):1-48

Berkley HA, Kendall BE, Mitarai S, Siegel DA (2010) Turbulent dispersal promotes species coexistence. Ecol Lett 13:360-371

Bertelsmeier C, Courchamp F (2014) Future ant invasions in France. Environ Conserv 41(2):217-228

Bertelsmeier C, Amauri A, Blight O, Confais A, Diez L, Jourdan $\mathrm{H}$, Orivel J, Saint Germès N, Courchamp F (2015a) Different behavioural strategies among seven highly invasive ant species. Biol Invasions 17:2491-2503

Bertelsmeier C, Avril A, Blight O, Jourdan H, Courchamp F (2015b) Discovery-dominance trade-off among widespread invasive ant species. Ecol Evol 5(13):2673-2683

Bertelsmeier C, Luque GM, Hoffmann BD, Courchamp F (2015c) Worldwide ant invasions under climate change. Biodivers Conserv 24:117-128. https://doi.org/10.1007/ s10531-014-0794-3

Bertelsmeier C, Ollier S, Avril A, Blight O, Jourdan H, Courchamp F (2016) Colony-colony interactions between highly invasive ants. Basic Appl Ecol 17:106-114

Bertelsmeier C, Ollier S, Liebhold A, Keller L (2017) Recent human history governs global ant invasion dynamics. Nat Ecol Evol 1(7):0184

Bertelsmeier C, Ollier S, Liebhold AM, Brockerhoff EG, Ward D, Keller L (2018) Recurrent bridgehead effects accelerate global alien ant spread. Proc Natl Acad Sci 115(21):5486-5491

Bhatkar A, Whitcomb W (1970) Artificial diet for rearing various species of ants. Fla Entomol 53:229-232

Blackburn TM, Pyšek P, Bacher S, Carlton JT, Duncan RP, Jarošík V, Wilson JRU, Richardson DM (2011) A proposed unified framework for biological invasions. Trend Ecol Evol 26(7):333-339

Blancafort X, Gómez C (2006) Downfall of pollen carriage by ants after Argentine ant invasion in two Mediterranean Euphorbia species. Vie et Milieu 56:243-246

Blight O, Renucci M, Tirard A, Orgeas J, Provost E (2010) A new colony structure of the invasive Argentine ant (Linepithema humile) in southern Europe. Biol Invasions 12:1491-1497
Blight O, Berville L, Vogel V, Hefetz A, Renucci M, Orgeas J, Provost E, Keller L (2012) Variation in the level of aggression, chemical and genetic distance among three supercolonies of the Argentine ant in Europe. Mol Ecol 21:109-4121

Blight O, Josens R, Bertelsmeier C, Abril S, Boulay R, Cerdá X (2017) Differences in behavioural traits among native and introduced colonies of an invasive ant. Biol Invasions 19:1389-1398

Boomsma JJ, Brouwer AH, Van Loon AJ (1990) A new polygynous Lasius species (Hymenoptera, Formicidae) from Central Europe. II. Allozymatic confirmation of species status and social structure. Insect Soc 37:353-375

Boulay R, Cerdá X, Simon T, Roldan M, Hefetz A (2007) Intraspecific competition in the ant Camponotus cruentatus: should we expect the 'dear enemy' effect? Anim Behav 74:985-993

Buczkowski G, Bennett GW (2007) Protein marking reveals predation on termites by the woodland ant, Aphaenogaster rudis. Insect Soc 54:219-224

Burchill AT, Moreau CS (2016) Colony size evolution in ants: macroevolutionary trends. Insect Soc 63:291-298

Carere C, Audebrand C, Rödel H, d'Ettorre P (2018) Individual behavioural type and group performance in Formica fusca ants. Behav Process 157:402-407

Carpintero S, Reyes-López J (2008) The role of competitive dominance in the invasive ability of the Argentine ant (Linepithema humile). Biol Invasions 10:25-35

Cerdá X, Retana J, Cros S (1997) Thermal disruption of transitive hierarchies in Mediterranean ant communities. J Anim Ecol 66:363-374

Christensen C, Radford AN (2017) Dear enemies or nasty neighbors? Causes and consequences of variation in the responses of group-living species to territorial intrusions. Behav Ecol 29(5):1004-1013

Cremer S, Ugelvig LV, Lommen STE, Petersen KS, Pedersen JS (2006) Attack of the invasive garden ant: aggression behaviour of Lasius neglectus (Hymenoptera: Formicidae) against native Lasius species in Spain. Myrmecogical News 9:13-19

Czechowski W, Radchenko A, Czechowska W, Vepsäläinen K (2012) The ants of Poland with reference to the myrmecofauna of Europe. Fauna Poloniae 4. Natura optima dux Foundation, Warsaw

D'Ettorre P, Lenoir A (2010) Nestmate recognition. In: Lach L, Parr CL, Abbott KL (eds) Ant ecology. Oxford University Press, Oxford

Diaz M, Abril S, Enríquez ML, Gómez C (2014) Assessment of the Argentine ant invasion management by means of manual removal of winter nests in mixed cork oak and pine forests. Biol Invasions 16:315-327

Diez JM, D’Antonio CMD, Dukes JS, Grosholz ED, Olden JD, Sorte CJB, Blumenthal DM, Bradley BA, Early R, Ibáñez I, Jones SJ, Lawler JJ, Miller LP (2012) Will extreme climatic events facilitate biological invasions? Front Ecol Environ 10:249-257

DiGirolamo LA, Fox LR (2006) The influence of abiotic factors and temporal variation on local invasion patterns of the argentine ant (Linepithema humile). Biol Invasions $8(2): 125-135$ 
Dimarco RD, Farji-Brener AG, Premolia AC (2010) Dear enemy phenomenon in the leaf-cutting ant Acromyrmex lobicornis: behavioral and genetic evidence. Behav Ecol 21:304-310

Drescher J, Feldhaar H, Blüthgen N (2010) Interspecific aggression and resource monopolization of the invasive ant Anoplolepis gracilipes in Malaysian Borneo. Biotropica 43(1):93-99

Early R, Bradley BA, Dukes JS, Lawler JJ, Olden JD, Blumenthal DM, Gonzalez P, Grosholz ED, Ibañez I, Miller LP, Sorte CJB, Tatem AJ (2016) Global threats from invasive alien species in the twenty-first century and national response capacities. Nat Commun 7:12485

Espadaler X, Tartally A, Schultz R, Seifert B, Nagy Cs (2007) Regional trends and preliminary results on the local expansion rate in the invasive garden ant, Lasius neglectus (Hymenoptera, Formicidae). Insectes Sociaux 54(3):293-301

Fisher J (1954) Evolution and bird sociality. In: Hardy AC, Ford EB, Huxley FB (eds) Evolution as a process. Allen \& Unwin, London, pp 71-83

Fournier A, Barbet-Massin M, Rome Q, Courchamp F (2017) Predicting species distribution combining multi-scale drivers. Glob Ecol Conserv 12:215-226

Friard O, Gamba M, Fitzjohn R (2016) BORIS: a free, versatile open-source event-logging software for video/audio coding and live observations. Methods Ecol Evol 7:1325-1330

Frizzi F, Bartalesi V, Santini G (2017) Combined effects of temperature and interspecific competition on the mortality of the invasive garden ant: Lasius neglectus: a laboratory study. J Therm Biol 65:76-81

Gibb H, Parr CL (2010) How does habitat complexity affect ant foraging success? a test using functional measures on three continents. Oecologia 164(4):1061-1073

Giraud T, Pedersen JS, Keller L (2002) Evolution of supercolonies: the Argentine ants of southern Europe. Proc Nation Acad Sci 99(9):6075-6079

Gómez K, Espadaler X (2005) La hormiga argentina. Documentos Técnicos de Conservación, II Época, 12. Conselleria de Medi Ambient, 68

Gómez C, Oliveras J (2003) Can the Argentine ant (Linepithema humile Mayr) replace native ants in myrmecochory? Acta Oecol 24:47-53

Gómez C, Pons P, Bas JM (2003) Effects of the Argentine ant Linepithema humile on seed dispersal and seedling emergence of Rhamnus alaternus. Ecography 26:532-538

Grangier J, Le Breton J, Dejean A, Orivel J (2007) Coexistence between Cyphomyrmex ants and dominant populations of Wasmannia auropunctata. Behav Process 74(1):93-96

Haskins CP, Haskins EF (1965) Pheidole megacephala and Iridomyrmex humilis in Bermuda-equilibrium or slow replacement. Ecology 46:736-740

Haskins CP, Haskins EF (1988) Final observations on Pheidole megacephala and Iridomyrmex humilis in Bermuda. Psyche (Cambridge, Mass) 95(3-4):177-184

Heinze J, Foitzik S, Hippert A, Hölldobler B (1996) Apparent dear enemy phenomenon and environment-based recognition cues in the ant Leptothorax nylanderi. Ethology 102:510-522
Holway DA, Suárez AV (1999) Animal behavior: an essential component of invasion biology. Trends Ecol Evol 14(8):328-330

Holway DA, Lach L, Suárez AV, Tsutsui ND, Case TJ (2002) The causes and consequences of ant invasions. Annu Rev Ecol Syst 33:181-233

Jackson MC (2015) Interactions among multiple invasive animals. Ecology 96(8):2035-2041

Jeschke JM (2014) General hypotheses in invasion ecology. Diver Distrib 20(11):1229-1234

Jumbam KR, Jackson S, Terblanche JS, McGeoch MA, Chown SL (2008) Acclimation effects on critical and lethal thermal limits of workers of the Argentine ant, Linepithema humile. J Insect Physiol 54:1008-1014

Keller RP, Geist J, Jeschke JM, Kühn I (2011) Invasive species in Europe: ecology, status, and policy. Environ Sci Eur 23(1)

Kleineidam CJ, Heeb EL, Neupert S (2017) Social interactions promote adaptive resource defense in ants. PLOS ONE 12(9): 0183872

Kneitel JM, Chase JM (2004) Trade-offs in community ecology: linking spatial scales and species coexistence. Ecol Lett 7:69-80

Krushelnycky PD, Gillespie RG (2010) Correlates of vulnerability among arthropod species threatened by invasive ants. Biodivers Conserv 19:1971-1988

Lake E, Cutting K, Hough-Goldstein J (2011) Integrating biological control and native plantings to restore sites invaded by mile-a-minute weed, Persicaria perfoliata in the MidAtlantic USA. In: Proceedings of the III international symposium on biological control of weeds, Waikoloa, Hawaii, USA, 254 p

LeBrun EG, Tillberg CV, Suarez AV, Folgarait PJ, Smith CR, Holway DA (2007) An experimental study of competition between fire ants and Argentine ants in their native range. Ecology 88:63-75

LeBrun EG, Abbott J, Gilbert LE (2013) Imported crazy ant displaces imported fire ant, reduces and homogenizes grassland ant and arthropod assemblages. Biol Invasions 15:2429-2442

Leung B, Roura-Pascual N, Bacher S, Heikkilä J, Brotons L, Burgman MA, Dehnen-Schmutz K, Essl F, Hulme PE, Richardson DM, Sol D, Vilà M, Rejmanek M (2012) TEASIng apart alien species risk assessments: a framework for best practices. Ecol Lett 15(12):1475-1493

Lieberburg I, Kranz PM, Seip A (1975) Bermudian ants revisited: the status and interaction of Pheidole megacephala and Iridomyrmex humilis. Ecology 56:473-478

Lowe S, Browne M, Boudjelas S (2000) 100 of the world's worst invasive alien species. A selection from the global invasive species database. Invasive Species Specialist Group, Auckland, New Zealand

Maák I, Camera J, Casacci LP, Barbero F, Trigos-Peral G, Ślipiński P, Bonelli S, Zaccagno M, Witek M (2019) The influence of colony traits on the collective behaviour of Myrmica scabrinodis ants. Insect Conserv Divers 12:481-491

Maynard Smith J (1982) Evolution and the theory of games. Cambridge University Press, Cambridge 
Morrison LW (1996) Community organisation in a recently assembled fauna: the case of Polynesian ants. Oecologia 107:243-256

Nagy C, Tartally A, Vilisics F, Merkl O, Szita É, Rédei D, Csősz S, Szövényi G, Markó V (2009) Effects of the invasive garden ant, Lasius neglectus van Loon, Boomsma and Andrásfalvy, 1990 (Hymenoptera: Formicidae), on arthropod assemblages: pattern analyses in the type supercolony. Myrmecol News 12:171-181

Passera L (1994) Characteristics of tramp species. In: Williams DF (ed) Exotic ants: biology, impact, and control of introduced species. Westview Press, Boulder, Colorado, pp 23-43

R Core Team (2017) R: a language and environment for statistical computing. https://www.R-project.org/

Ricciardi A, Blackburn TM, Carlton JT, Dick JT, Hulme PE, Iacarella JC, Pyšek P (2017) Invasion science: a horizon scan of emerging challenges and opportunities. Trends Ecol Evol 32(6):464-474

Roura-Pascual N, Suarez AV, Gómez C, Pons P, Touyama Y, Wild AL, Towsend Peterson A (2004) Geographic potential of Argentine ants (Linepithema humile Mayr) in the face of global climate change. Proc R Soc Lond Biol Sci 271(1557):2527-2535

Russell L (2019) Emmeans: estimated marginal means, aka least-squares means. R package version 1.4.1. https:// CRAN.R-project.org/package=emmeans

Sagata K, Lester PJ (2009) Behavioural plasticity associated with propagule size, resources and the invasion success of the Argentine ant Linepithema humile. J Appl Ecol 46:19-27

Sarty M, Abbott KL, Lester PJ (2006) Habitat complexity facilitates coexistence in a tropical ant community. Oecologia 149(3):465-473

Scharf I, Pamminger T, Foitzik S (2011) Differential response of ant colonies to intruders: attack strategies correlate with potential threat. Ethology 117(8):731-739

Simberloff D (2009) The role of propagule pressure in biological invasions. Annu Rev Ecol Evol Syst 40:81-102

Simberloff D, Von Holle B (1999) Positive interactions on nonindigenous species: invasional meltdown? Biol Invasions 1:21-32

Spicer Rice ES, Silverman J (2013) Propagule pressure and climate contribute to the displacement of Linepithema humile by Pachycondyla chinensis. PLoS ONE 8:e56281

Strayer DL, Eviner VT, Jeschke JM, Pace ML (2006) Understanding the long-term effects of species invasions. Trends Ecol Evol 21(11):645-651

Stukalyuk SV (2017) The beginning of the invasion of Lasius neglectus (Hymenoptera, Formicidae) in Kiev (Ukraine). Entomol Rev 97(8):1063-1065
Suárez AV, Tsutsui ND, Holway DA, Case TJ (1999) Behavioral and genetic differentiation between native and introduced populations of the Argentine ant. Biol Invasions $1: 43-53$

Suárez AV, Holway DA, Ward PS (2005) The role of opportunity in the unintentional introduction of nonnative ants. Proc Natl Acad Sci USA 102:17032-17035

Thomas MB, Reid AM (2007) Are exotic natural enemies an effective way of controlling invasive plants? Trends Ecol Evol 22:447-453

Trigos-Peral G, Reyes-López JL (2016) Quite a cosmopolitan neighborhood: a new record of Cardiocondyla obscurior Wheeler, 1929 together with Cardiocondyla mauritanica Forel, 1890 and Linepithema humile (Mayr, 1868) (Hymenoptera, Formicidae). Boletín de la Asociación española de Entomología 40(3-4):503-506

Trigos-Peral G, Gómez K, Reyes-López JL (2020) Contribution to the knowledge of the invasive species in Andalusia: First records of exotic ant species (Hym., Formicidae) in Axarquía (Torre del Mar, Málaga, Spain). Boletín de la Asociación española de Entomología 44(1-2): 239-244

Ugelvig LV, Drijfhout FP, Kronauer DJC, Boomsma JJ, Pedersen JS, Cremer S (2008) The introduction history of invasive garden ants in Europe: integrating genetic, chemical and behavioural approaches. BMC Biol 6:11

Venables WN, Ripley BD (2002) Modern applied statistics with $\mathrm{S}$, 4th edn. Springer, New York. ISBN 0-387-95457-0

Vogel V, Pedersen JS, d'Ettorre P, Lehmann L, Keller L (2009) Dynamics and genetic structure of argentine ant supercolonies in their native range. Evolution 63(6):1627-1639

Vonshak M, Gordon DM (2015) Intermediate disturbance promotes invasive ant abundance. Biol Conserv 186:359-367

Wetterer JK (2017) Invasive ants of Bermuda revisited. J Hymenopt Res 54:33-41

Wetterer JK, Wild AL, Suarez AV, Roura-Pascual N, Espadaler X (2009) Worldwide spread of the Argentine ant, Linepithema humile (Hymenoptera: Formicidae). Myrmecol News 12:187-194

Wickham H (2016) ggplot2: elegant graphics for data analysis. Springer, New York

Zheng J, Mao R, Zhang R (2008) Competitive interactions between the yellow crazy ant and the red imported fire ant (Hymenoptera: Formicidae). J Entomol Sci 43:331-336

Publisher's Note Springer Nature remains neutral with regard to jurisdictional claims in published maps and institutional affiliations. 